\title{
El conocimiento pedagógico del contenido en tres docentes ingenieros: un acercamiento desde el análisis multimodal del discurso
}

The pedagogical content knowledge of three engineers professors: an approach from multimodal discourse analysis

\author{
Volumen 17, Número 1 \\ Enero-Abril \\ pp. 1-30
}

Este número se publicó el $1^{\circ}$ de enero de 2017

DOI: http://dx.doi.org/10.15517/aie.v17i1.27275

César Marcelo Díaz Pacheco

Revista indizada en REDALYC, $\underline{\text { SCIELO }}$

Revista distribuida en las bases de datos:

LATINDEX, DOAJ, REDIB, IRESIE, CLASE, DIALNET, SHERPA/ROMEO, QUALIS-CAPES, MIAR

Revista registrada en los directorios:

ULRICH'S, REDIE, RINACE, OEI, MAESTROTECA, PREAL, CLACSO 


\title{
El conocimiento pedagógico del contenido en tres docentes ingenieros: Un acercamiento desde el análisis multimodal del discurso
}

\author{
The pedagogical content knowledge of three engineers professors: An approach from \\ multimodal discourse analysis
}

\section{César Marcelo Díaz Pacheco ${ }^{1}$}

Resumen: Este artículo aporta una mirada reflexiva a aquellos docentes que no tienen formación pedagógica, pero que están interesados en desarrollar una visión crítica de los procesos de formación académica. Para esto, se profundiza en el conocimiento pedagógico del contenido manifestado en las prácticas de aula de tres académicos que no tienen estudios en Pedagogía, pero que imparten docencia en Educación Superior. Por medio del análisis multimodal del discurso, se exploraron las interacciones semióticas a través de la observación de las actividades típicas desarrolladas al interior del salón de clases, con el objetivo de describir las prácticas docentes de tres ingenieros de una escuela de Ingeniería Civil Industrial de una universidad tradicional chilena. Así, se realizó un estudio de casos múltiple, mediante un registro audiovisual de dos sesiones de aula y una entrevista semi-estructurada por cada uno; de este modo, se analizó el discurso de aula con el propósito de develar cómo los académicos despliegan los recursos semióticos que articulan para la formación profesional de sus aprendices. Los hallazgos nos muestran que el profesorado genera un discurso de aula marcado por el conocimiento particular de su materia; dado esto, los medios y modos semióticos que despliega varían según el tipo de conocimiento disciplinar que se produce. Como bien sabemos, la formación de competencias profesionales conlleva la integración de diversos conocimientos para el logro de estas, por lo que la relación entre contenido disciplinar y conocimiento pedagógico debiera ser más bien intrínseca e inclusiva. Lo anterior, implica que los docentes -independiente de su formación profesional- debieran manejar representaciones culturalmente construidas, no solo de sus materias y contenidos disciplinares, sino también de su accionar pedagógico.

Palabras clave: conocimiento pedagógico del contenido, multimodalidad, análisis del discurso, semiótica, ingeniería civil, docentes universitarios

\begin{abstract}
This paper provides a reflexive view to those professors with no pedagogical formation, but with an interest in developing a critical point of view about the processes of academic training. It is done a deep analysis of the pedagogical content knowledge manifested in the classroom practices of three professors with no studies in the field of Pedagogy, but that are teaching in Higher Education. Through multimodal discourse analysis, semiotic interactions were explored through the observation of typical activities developed in the classroom, with the aim of describing the teaching practices of three engineers of an Industrial Engineering School of a traditional Chilean university. A multiple case study was conducted using an audiovisual record of two classroom sessions and a semi-structured interview to each professor. This way, the classroom speech was analyzed to discover how the professors reveal the semiotic resources that they articulate for the professional education of their students. The results show us that the professors generate a classroom speech influenced by the particular knowledge about their field and accordingly, the semiotic means and the semiotic modes that they reveal vary according to the kind of disciplinary knowledge that is produced. As we well know, in order to develop professional skills, teaching involves the integration of diverse knowledge, and because of that, the relationship between the disciplinary content and the pedagogical knowledge should be rather intrinsic, or inclusive. This implies that the professors independent of their professional education - should manage culturally constructed representations, not only about their field and contents, but also about their pedagogical action.
\end{abstract}

Keywords: pedagogical content knowledge, multimodality, discourse analysis, semiotics, civil engineering, university teachers

\footnotetext{
1 Profesor de Castellano y Comunicación de la Pontificia Universidad

Católica de Valparaíso, Chile. Magíster en Educación.
}

Dirección electrónica: cesar.diaz@pucv.cl

Artículo recibido: 2 de octubre, 2015

Enviado a corrección: 28 de junio, 2016

Aprobado: 21 de noviembre, 2016 


\section{Introducción al problema de investigación ${ }^{2}$}

Tradicionalmente, en el interior de las casas de estudios universitarios es posible observar cómo una gran parte de los académicos corresponden a titulados de distintas áreas que enseñan sus conocimientos a futuros profesionales. En el caso de los ingenieros, ellos no han sido formalmente preparados para enseñar sus disciplinas, por lo que la experticia de enseñanza la han desarrollado a través de su formación continua, durante la experiencia adquirida en el ejercicio del oficio docente, más que en su formación inicial (Navío, 2006).

Al respecto, la ausencia de políticas educativas enfocadas sobre la formación profesional ha tenido un impacto en la enseñanza de acuerdo con lo que se indica en el informe $^{3}$ de la OCDE del 2009. Este manifiesta que al interior del aula universitaria prevalecen aún métodos tradicionales de enseñanza en los cuales se privilegia la memorización de contenidos, el aprendizaje individual y la reproducción de aprendizajes. Brunner (2008) postula que la visión tradicionalista de la docencia universitaria se caracteriza por ser eminentemente profesionalizante, en esta los estudiantes poseen un rol pasivo, ya que se privilegian métodos de enseñanza centrados en los contenidos disciplinares, por lo que el aprendizaje continúa siendo visto como un mero proceso de adquisición y transmisión de conocimientos, débilmente entrelazado con la práctica reflexiva, que supone forma el núcleo de las carreras universitarias.

La propuesta de Shulman (1987) sobre conocimiento pedagógico del contenido aborda de modo concreto y reflexivo la implicancia del conocimiento sobre la enseñanza de los profesores, no obstante, qué se sabe sobre este tipo de conocimiento en quienes imparten docencia en educación superior, pero que no tienen formación inicial de estudios en pedagogía. Asimismo, cabe preguntarnos cómo se enseña una materia del campo de la Ingeniería. ¿Qué tipos de conocimientos poseen quienes enseñan en esa área? ¿Qué recursos semióticos son desplegados por estos profesionales en la sala de clases? Dado lo anterior, este artículo busca dar respuesta a lo siguiente: ¿Cómo se manifiesta el conocimiento pedagógico del contenido en las prácticas docentes de tres ingenieros que se desempeñan como académicos en una universidad tradicional chilena?

Consecuente con estas preguntas, este trabajo se enmarca dentro de la investigación cualitativa y presenta un perfil multimodal manifestado en un estudio de casos múltiple de tres ingenieros que imparten docencia en una escuela de Ingeniería Civil Industrial de una

\footnotetext{
2 Investigación enmarcada en el Proyecto Fondecyt №1130684. Escuela de Pedagogía. Pontificia Universidad Católica de Valparaíso. Región de Valparaíso, Chile.

3 Revisión de Políticas Nacionales de Educación: La Educación Superior en Chile. Organización para la Cooperación y el Desarrollo Económico y el BIRD/Banco Mundial, 2009.
} 
universidad tradicional chilena. Así, en concordancia con esta propuesta, el objetivo general de este estudio es describir las prácticas docentes de tres ingenieros civiles industriales a través del análisis multimodal del discurso, con el fin de analizar el conocimiento pedagógico del contenido presente en este grupo de académicos.

\section{Marco teórico}

\subsection{Conocimiento pedagógico del contenido y conocimiento cotidiano: una convergencia de saberes}

Las prácticas de aula y los conocimientos que giran en torno a ella se construyen de manera social y dialógica, producto de la interacción simbólica articulada al interior de estos contextos de formación académica. Desde la mirada de Bernstein (2000), la distribución y regulación del conocimiento en los centros de educación superior se lleva a cabo a través del dispositivo pedagógico. El dispositivo comienza en el campo de la producción donde el conocimiento se produce y posiciona, en este caso particular, en los contextos científicos del campo de la Ingeniería. Luego, "pasa por el campo de la re-contextualización donde los discursos del campo de producción son seleccionados, apropiados y reposicionados como conocimiento educativo" (Manghi, 2009, p. 62), siendo parte fundamental del dispositivo las organizaciones estatales que se encargan del currículum universitario. El dispositivo finaliza cuando los discursos se llevan al campo de la reproducción donde la transmisión pedagógica y adquisición del conocimiento (Maton, 2014) se "concretiza" al interior del aula universitaria por medio de sus agentes educativos.

Mirando la enseñanza en el aula y la interacción construida en este espacio particular, Lee S. Shulman (1987) propone que quien se dedica a la docencia debiera tener un conocimiento base que incluya, entre otras, las siguientes categorías:

A. Conocimiento disciplinar: conocimiento del tema particular sobre la materia.

B. Conocimiento didáctico general: se refiere a los principios y estrategias generales de manejo y organización de la clase.

C. Conocimiento curricular: conocimiento de los programas y materiales diseñados para la enseñanza, conocimiento de los objetivos, contenidos, lineamientos educativos, entre otros.

D. Conocimiento sobre las concepciones y características de sus alumnos: esta categoría hace referencia al conocimiento del docente sobre sus estudiantes en torno a comprensiones erróneas, dificultades habituales, conocimiento previo, entre otras. 
E. Conocimiento pedagógico del contenido: relación y convergencia entre los distintos saberes pedagógicos y disciplinarios que le permite al docente hacer enseñable el contenido.

En la propuesta de Shulman (1987), se observa la ausencia de un tipo de conocimiento fundamental en los procesos de enseñanza articulados al interior de aula: el conocimiento cotidiano (Pozo y Gómez, 1998). Este tipo de conocimiento, observado a nivel de interacción profesor - alumno, suele presentarse como un conjunto de teorías con un fuerte significado cultural y socialmente compartidas, lo que hace que su erradicación sea aún más improbable e innecesaria del contexto educativo dado su alto valor pragmático, adaptativo y cultural (todos decimos que "sale el sol" o que las cosas "caen por su propio peso" con independencia de nuestro conocimiento sobre la física) (Pozo y Gómez, 1998).

A diferencia de las teorías implícitas,

las teorías científicas tienen un carácter explícito, de modo que su construcción requiere del estudiante una toma de consciencia y explicitación de las relaciones entre los modelos interpretativos que le proporcionan la ciencia y sus propias concepciones alternativas. Mientras que en el conocimiento cotidiano pensamos con las teorías, actuar como un científico implica pensar en las teorías. (Khun, Amsel y O’Loughlin, 1988, citado en Pozo y Gómez, 1998, p. 146)

Los conceptos provenientes del mundo cotidiano y sus formas de comunicarlos corresponden a un discurso horizontal, accesible a todas las personas, tiende a ser un discurso local, dependiente y específico del contexto, tácito y de múltiples significados. La enseñanza de las ciencias promueve que el aprendiz avance gradualmente desde el conocimiento cotidiano hacia el conocimiento particular de una disciplina, representado a través de un discurso vertical o académico el cual corresponde a uno de tipo especializado, coherente, independiente del contexto, explícito y jerárquicamente organizado (Bernstein, 2000).

A partir de la noción que las disciplinas se constituyen como espacios tanto discursivos como conceptuales, desde esta perspectiva investigativa, aprender los "contenidos" de cada materia es un proceso que consiste no solo en apropiarse de su sistema conceptual metodológico (Hall y López, 2011), sino también de sus prácticas discursivas características, por lo que la importancia de considerar que, previa y paralelamente a la enseñanza de los modos discursivos propios de cada disciplina, es necesario también sumar espacios 
destinados al ejercicio de prácticas semióticas de andamiaje y transmisión del conocimiento basadas en saberes pedagógico-discursivos que no conciernen exclusivamente a la especificidad discursiva del campo disciplinar. De esta forma, se torna fundamental en las dinámicas de alfabetización científica la combinación discursiva de conocimientos articulada en la práctica docente, con el fin de que los estudiantes dominen gradualmente el discurso vertical de una determinada disciplina.

\subsection{Prácticas, discurso y concepciones del docente: una construcción de significados}

Dentro de esta línea investigativa, el concepto de práctica docente pone especial foco de atención en el actuar del profesor, en el modo en que él se desenvuelve, se comporta y relaciona; esto es, la caracterización de sus hábitos, acciones y estilos de enseñanza en un contexto educativo particular. Para ello, se destaca la idea del rol activo y mediador del docente "como orientador y acompañante del proceso de enseñanza-aprendizaje de sus estudiantes, así como su carácter de interlocutor privilegiado" (Gaitán y Jaramillo, 2007, p.18) en la construcción de significados orquestada por este, en su mediación semiótica en el aula.

En el desarrollo de estas prácticas de enseñanza, fundamental es el rol que juega la construcción y multiplicidad de recursos pedagógicos utilizados por el profesor para promover el aprendizaje significativo en sus aprendices (Vygotsky, 1979; 1987). Al respecto, investigaciones sobre alfabetización y disciplinas desarrolladas por Martin (2009) y O'Halloran (2007) revelan una mirada integral de la docencia, la cual plantean que ya no se construye exclusivamente mediante el lenguaje oral o escrito, sino que se complementa con base en el uso de múltiples modos o recursos semióticos, tales como: gráficos, mapas e imágenes, entre otros, puestos en juego por el docente para crear significado y así regular la producción de conocimiento y aprendizaje de sus estudiantes (Hood, 2009).

Para Bernstein (1999), el discurso de aula se origina en un contexto científico disciplinar y, tras pasar por un proceso de re-contextualización en el que se selecciona para ser parte del currículum oficial, es reproducido y transformado significativamente en la sala de clases. De esta forma, el discurso pedagógico viene a ser el principal modo que tienen los profesores para interactuar con los estudiantes, permitiendo desarrollar y fortalecer - desde una disciplina particular - competencias y habilidades especializadas (Bernstein, 1999). Así, resulta relevante que el docente reflexione sobre cómo ha de enseñar, con el fin de evaluar 
su discurso pedagógico (actitud hacia la ciencia, recursos de aprendizaje, conocimiento científico, entre otros) frente a los estudiantes, pues el idioma de la ciencia debe ser un proceso configurado por el profesor mediante un andamiaje (Córdova, Melo, Bacigalupo y Manghi, 2016), porque este aprendizaje no es automático o natural, es específico y debe ser enseñado mediante una regulación del conocimiento (Lemke, 2008).

En este sentido, el discurso pedagógico se relaciona estrechamente con las formas en que los docentes conciben el contenido que enseñan, el curriculum, la organización universitaria y los procesos de aprendizaje de los estudiantes (Rojas, 2014). Este tipo de concepciones o creencias docentes incluyen las expectativas, percepciones o formas de significación de la realidad. También integran ideas, pensamientos, teorías implícitas, entre otras, en un sistema interconectado de conocimientos y saberes que confluyen en el pensamiento del profesor (Rojas, 2014).

Según Imbernon (2005), estas concepciones o creencias docentes "se transforman en saberes profesionales sistematizados solo cuando los profesores tienen la oportunidad de reflexionar colectivamente sobre su práctica y pueden pensarla y organizarla desde una perspectiva más teórica" (Rojas, 2014, p.112). Este proceso requiere que los académicos sistematicen sus ideas en torno a su trabajo pedagógico y que las tensionen en canales de discusión y divulgación (Shulman, 1999).

Así, para indagar en las competencias, habilidades y actitudes de los docentes para el desarrollo de su práctica en aula, se torna ineludible la tarea de identificar sus creencias y conocimientos característicos, principalmente, aquellos necesarios para impulsar una transformación del proceso enseñanza-aprendizaje que permita entregar al mundo laboral profesionales que asuman y enfrenten los desafíos de manera eficiente e innovadora (Salazar, Chiang y Muñoz, 2016).

\subsection{Análisis multimodal del discurso: una mirada semiótica de la enseñanza}

Nuestra aproximación a la investigación de la enseñanza de la Ingeniería se sitúa desde la vereda de la semiótica social, esbozada inicialmente por Halliday (1979) en la tradición funcional sistémica y desarrollada posteriormente por Hodge y Kress (1988) y Kress y van Leeuwen (1996), entre otros. La semiótica social, interesada en cómo se construyen los significados en la comunicación humana y, concretamente, en el uso que hacen las personas de los recursos semióticos para crear actos comunicativos, prevé otros modos de comunicación aparte de los puramente verbales y sitúa los actos de significación en su 
contexto sociocultural e ideológico concreto: esto es, todo modo, al utilizarse, recibe una motivación social conformada por la cultura. Se entenderá por modo, entonces, cualquier forma de uso de recurso o vía disponible en el contexto comunicativo que se emplee con el propósito de crear significados (Kress, Leite-García y van Leeuwen, 2000).

Sobre los modos o recursos semióticos, la perspectiva multimodal (proveniente de la semiótica social) nos revela que el despliegue del docente en el aula se amplía entonces desde la consideración del uso del lenguaje oral y escrito hacia la inclusión de otros elementos, por ejemplo: dibujos, fotos, mapas, tablas, gráficos, entre otros (Badillo, Córdova, Manghi y Haas, 2013).

Uno de los aspectos importantes que entran en juego sobre el potencial semiótico en el discurso áulico son los gestos deícticos desplegados por el profesor en su interacción pedagógica. Así como las neurociencias han recogido las primeras clasificaciones de los gestos, estas también han sido consideradas como antecedentes útiles para la perspectiva multimodal de la semiótica social. Martinec (2004) describe los gestos como un sistema semiótico y su relación con el habla en la interacción cara a cara, profundiza en la relación entre la representación de diferentes tipos de procesos y los recursos gestuales para realizarlos, enfatizando en los gestos indexicales o deícticos.

A diferencia de la mirada cognitiva, este autor considera que los gestos, como recursos semióticos, se emplean de manera sistemática y podrían describirse como un sistema de oposiciones semánticas, lo que hace posible su descomposición y descripción gramatical (Martinec, 2004). Su investigación propone una red sistémica de contrastes indexicales, tanto para el brazo, mano y dedos, considerando en cada uno las opciones para movimiento y detención.

En lo que se respecta a la variedad de medios o también llamados artefactos semióticos en el aula, en sintonía con investigaciones elaboradas en contextos escolares y universitarios por Kress, Jewitt, Ogborn y Tsatsarelis (2001), Baldry y Thibault (2006), Manghi (2013) y Farías y Araya $(2014$; 2015), estos se agrupan en tres tipos: medio interacción cara a cara, medios impresos y medios tecnológicos (ver Figura 1): 
Figura 1

Medios y modos semióticos

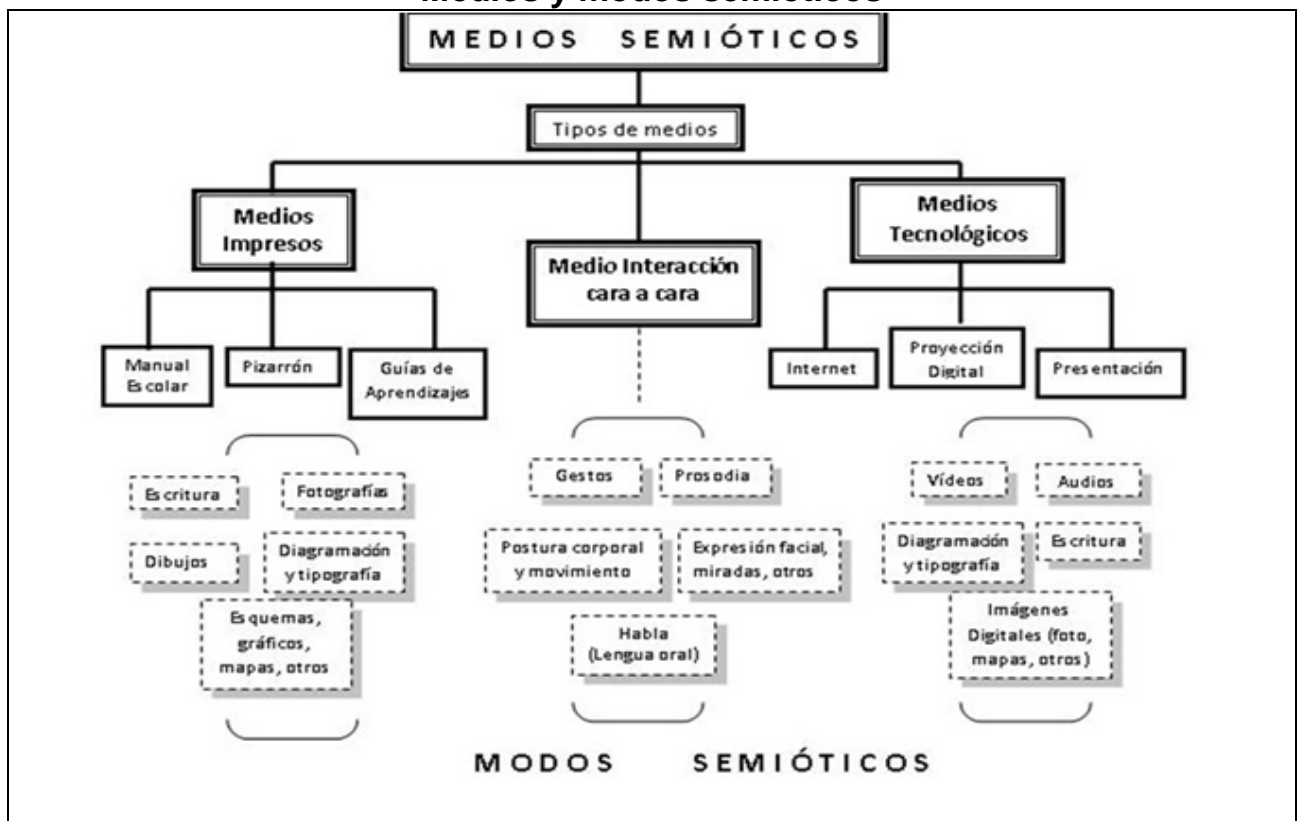

Fuente: Badillo, Córdova, Manghi y Haas (2013).

En la actualidad, los potenciales semióticos para representar y comunicar contenidos y procedimientos por enseñar están asociados inevitablemente al avance de las tecnologías, lo que posibilita incorporar cada vez más recursos semióticos para el diseño de la enseñanza de los contenidos del currículum universitario (Martins, 2006). Este fenómeno repercute, entre otras cosas, en las posibilidades de utilización de imágenes, artefactos materiales y plataformas virtuales, los cuales son seleccionados por los profesores para que los aprendices aprendan a partir de ellas (Manghi y Haas, 2015).

Desde este punto de vista, la perspectiva multimodal sobre la enseñanza y la comunicación constituye un desafío para quienes estudian dentro del campo del análisis del discurso en contextos educativos, pues permite ampliar la comprensión de los fenómenos de representación y de comunicación en la sala de clases.

Como una ruptura en las prácticas de enseñanza, estas "nuevas" prácticas semióticas del ámbito universitario nos obligan a mirar con atención las posibilidades de crear significado de manera intencionada por parte de los profesores en la mediación pedagógica. Lo anterior requiere pasar de una lógica de la enseñanza que incluía solo la modalidad discursiva a otra en situaciones problema, en donde el docente auspicie, modele, ilustre y retroalimente los desempeños idóneos como alternativas de solución. 
La formación universitaria basada en modelos centrados sobre el contenido disciplinar como objetivo primordial del aprendizaje está siendo modificada debido al acelerado cambio de los conocimientos, el acceso y la manera en cómo fluye y, en consecuencia, la provisionalidad de los saberes (Irigoyen, Jiménez y Acuña, 2011). Dentro de estas dinámicas de cambio, el desafío es generar mayores oportunidades para comprender textos multimodales de manera crítica y reflexiva (Farías y Araya, 2014) más allá del consumo pasivo y reproductivo del conocimiento, avanzando hacia la formación de estudiantes que sepan diseñar, producir y distribuir textos multimodales (Kress, 2010) para participar de manera reflexiva, activa y propositiva una vez insertos tanto en el mundo laboral como en la vida ciudadana en general.

\section{Marco metodológico}

La aproximación al objeto de estudio se construye mediante una metodología cualitativa e involucra dos enfoques teórico-metodológicos estrechamente relacionados. El enfoque de la semiótica social (Martin y Rose, 2008) se ha utilizado para la recolección de los datos y el análisis multimodal del discurso de la vertiente de la semiótica social (Martin, 2009; Manghi, 2009) para explorarlos.

Este estudio exploratorio-descriptivo presenta un diseño metodológico correspondiente a un estudio de casos múltiple. Para esto, se emplearon instrumentos de recolección de datos cualitativos con el propósito de explorar y describir las interacciones simbólicas de aula y así poder interpretar la realidad tal como la experimentan sus protagonistas (Denzin y Lincoln, 2012). Según Robert Stake (2008), el estudio de casos debe aplicarse a situaciones que merezcan una mirada especial porque justamente se salen de la norma, en tanto sus características particulares los hacen especiales: en este caso, ingenieros que no poseen estudios formales de pedagogía, pero que imparten docencia en educación superior.

Para la selección de los sujetos de estudio, se consideraron los criterios pragmáticos propuestos por Vieytes (2004): de pertinencia (en cuanto a identificar los casos que pueden aportar más cantidad y calidad de información), de conveniencia (en cuanto a que el investigador no cause interferencias mayores en la situación y le sea posible posicionarse socialmente dentro del grupo) y disponibilidad (en cuanto se permita acceso libre y permanente a la situación a observar).

Para acceder e investigar la práctica docente, mediante una observación no participante, se tomó un registro audiovisual de un total de seis clases a tres académicos 
titulares de una escuela de Ingeniería civil industrial de una universidad tradicional chilena (ver Tabla 1). Posteriormente, se diseñaron y aplicaron tres entrevistas semi-estructuradas con el propósito de confrontar las concepciones de este grupo de ingenieros con el desarrollo de su propia práctica de enseñanza.

Tabla 1

Características de la muestra ESTUDIO DE CASOS MÚLTIPLE

\begin{tabular}{|c|c|c|c|}
\hline \multicolumn{4}{|c|}{ ESTUDIO DE CASOS MÚLTIPLE } \\
\hline Muestra de estudio & Sujeto 1 & Sujeto 2 & Sujeto 3 \\
\hline Edades Aproximadas & $45-55$ años & $45-50$ años & $45-55$ años \\
\hline $\begin{array}{lll}\text { Número de } & \text { clases } \\
\text { observadas }\end{array}$ & 2 & 2 & 2 \\
\hline Tiempo de grabación & $180 \mathrm{~min}$. & $180 \mathrm{~min}$. & $180 \mathrm{~min}$. \\
\hline $\begin{array}{l}\text { Nombre de las asignaturas } \\
\text { observadas }\end{array}$ & $\begin{array}{ll}\text { Fundamento } & \text { de } \\
\text { modelos } & \\
\text { probabilísticos } & \\
\end{array}$ & $\begin{array}{l}\text { Taller de creatividad } \\
\text { e innovación }\end{array}$ & $\begin{array}{l}\text { Introducción } \\
\text { modelamiento } \\
\text { discreto }\end{array}$ \\
\hline $\begin{array}{l}\text { Características de los } \\
\text { cursos observados }\end{array}$ & $\begin{array}{l}\text { 1er año de formación } \\
\text { universitaria, curso } \\
\text { compuesto entre } 40 \text { - } \\
60 \text { estudiantes }\end{array}$ & $\begin{array}{l}2 \text { do año de } \\
\text { formación } \\
\text { universitaria, curso } \\
\text { compuesto entre } \\
90 \text { - } \\
90 \text { estudiantes }\end{array}$ & $\begin{array}{l}\text { 3er año de } \\
\text { formación } \\
\text { universitaria, curso } \\
\text { compuesto entre } \\
40-60 \text { estudiantes } \\
\end{array}$ \\
\hline Entrevistas Realizadas & 1 & 1 & 1 \\
\hline
\end{tabular}

Fuente: Elaboración propia.

En relación con la elaboración de las preguntas que conformaron las entrevistas, fue fundamental la revisión del plan de estudios y del perfil de titulación de la carrera. Esto ayudó a desprender las preguntas referidas, entre otras, a las categorías temáticas que no pudieron ser observadas en los registros audiovisuales: conocimiento curricular y conocimiento de los profesores sobre las características y concepciones particulares de sus estudiantes.

Para la aplicación de las entrevistas se aplicaron preguntas más o menos abiertas referidas principalmente a lo observado en los registros audiovisuales de las clases grabadas en torno a: regulación disciplinar, discurso didáctico instruccional y vinculación con el mundo cotidiano. Conjuntamente, se realizaron preguntas en torno a las dimensiones que no fueron abordadas en el registro audiovisual: manejo de instrumentos curriculares y conocimiento sobre las concepciones y características particulares de los estudiantes. Así, los entrevistados pudieron responder a ellas de manera libre y abierta.

Sobre la muestra, los tres sujetos de estudio fueron seleccionados de modo intencional a partir de ciertos criterios: un mínimo de cinco años de ejercicio en el rol, profesores jerarquizados, todos ellos ingenieros civiles industriales sin estudios formales en pedagogía y que se desempeñen en cursos iniciales de formación de la carrera, todos correspondientes a ramos disciplinares propios del campo ingenieril (ver Tabla 2). 
Tabla 2

Descripción de las asignaturas

\begin{tabular}{|c|c|c|}
\hline $\begin{array}{l}\text { Nombre de la } \\
\text { asignatura }\end{array}$ & Descripción de la asignatura observada & $\begin{array}{l}\text { Profesor que imparte la } \\
\text { asignatura observada }\end{array}$ \\
\hline $\begin{array}{l}\text { Fundamento de } \\
\text { modelos } \\
\text { probabilísticos }\end{array}$ & $\begin{array}{l}\text { Esta asignatura es una introducción a la } \\
\text { Teoría de la Probabilidad. Se desarrollan los } \\
\text { fundamentos matemáticos necesarios para } \\
\text { entender y modelar el comportamiento de } \\
\text { sistemas sujetos a incertidumbre, y resolver } \\
\text { problemas asociados. }\end{array}$ & Sujeto 1 \\
\hline $\begin{array}{lr}\text { Taller } & \text { de } \\
\text { creatividad } & \text { e } \\
\text { innovación } & \end{array}$ & $\begin{array}{l}\text { En este taller los alumnos exploran las } \\
\text { dimensiones de creatividad e innovación a } \\
\text { través de actividades que estimulan la } \\
\text { imaginación y la capacidad de observación. } \\
\text { Los alumnos desarrollan ideas novedosas } \\
\text { para productos y servicios. }\end{array}$ & Sujeto 2 \\
\hline $\begin{array}{l}\text { Introducción al } \\
\text { modelamiento } \\
\text { discreto }\end{array}$ & $\begin{array}{l}\text { Los modelos de sistemas discretos } \\
\text { constituyen un fundamento matemático } \\
\text { conceptual para una variedad de tópicos en el } \\
\text { ámbito de la disciplina, tales como } \\
\text { probabilidades, optimización discreta, redes, } \\
\text { simulación, matemáticas financieras, } \\
\text { programación de computadores y } \\
\text { modelamiento de sistemas de información, } \\
\text { entre otros. }\end{array}$ & Sujeto 3 \\
\hline
\end{tabular}

Fuente: Elaboración propia.

Así, las unidades de análisis quedaron conformadas del siguiente modo:

- Actividades Típicas de Aula (ATAs): En la propuesta de Sánchez, García, Rosales, de Sixte y Castellano (2008), estas ATAs aluden a diversas secuencias de actividades didácticas orquestadas por el docente y desarrolladas por sus estudiantes, las cuales integran intercambios que cumplen una tarea común en la sesión de clase.

- Medios y Modos semióticos: referido al uso articulado de artefactos y recursos semióticos desplegados de manera simultánea en uno o varios momentos específicos de la clase (Kress, Leite-García y van Leeuwen, 2000; Kress, 2010).

Este estudio de casos múltiple se estructuró mediante un trabajo de campo en el cual se recopilaron los datos en situaciones reales de clase, en un contexto de aula concreto y a partir de la observación del despliegue en el salón de clases de tres sujetos con características similares. Para estos fines, se les solicitó tanto a los académicos como a sus estudiantes la firma de un consentimiento informado que autoriza el ingreso a la clase, su registro audiovisual y la posibilidad de divulgar la sistematización de la información recopilada tanto de las clases observadas como de la entrevista realizada a cada informante. 


\section{Resultados y análisis}

Respecto al análisis de la información recogida, el primer nivel correspondió al levantamiento descriptivo y segmentación de las Actividades típicas de aula (ATAs) por cada grabación audiovisual respectivamente. Después de realizado esto, se analizó el despliegue de los medios-modos semióticos observados en cada una de las ATAs desde los procesos de construcción simbólica orquestados en el aula. También se observó la producción oral característica de cada uno de los académicos dentro de la sala de clases. Los fragmentos de producción oral que emergieron de las clases observadas, se denominaron y dividieron de la siguiente forma:

- Discurso disciplinar: correspondiente a la materia disciplinar, contenidos específicos o tema particular de la clase.

- Discurso didáctico general: asociado a las estrategias de manejo general, instructivo y organizativo de la clase.

- Discurso cotidiano: vinculado con las concepciones personales y de sentido común, ideas y creencias dependientes del contexto experiencial.

Para estos fines, se observó por minutos de clase cuando el profesor hacía referencia a temáticas del campo disciplinar, articulación de discurso didáctico instruccional o vinculación con el mundo cotidiano.

Para la sistematización de las transcripciones de las entrevistas se realizó un Análisis de Contenido (Cáceres, 2003; Mellado y Chaucono, 2015) al corpus lingüístico recopilado, siempre apuntando a las dimensiones constituyentes de nuestra propuesta de Conocimiento Pedagógico del Contenido, como se observa en la figura 2:

Figura 2

Reformulación de Conocimiento Pedagógico del Contenido

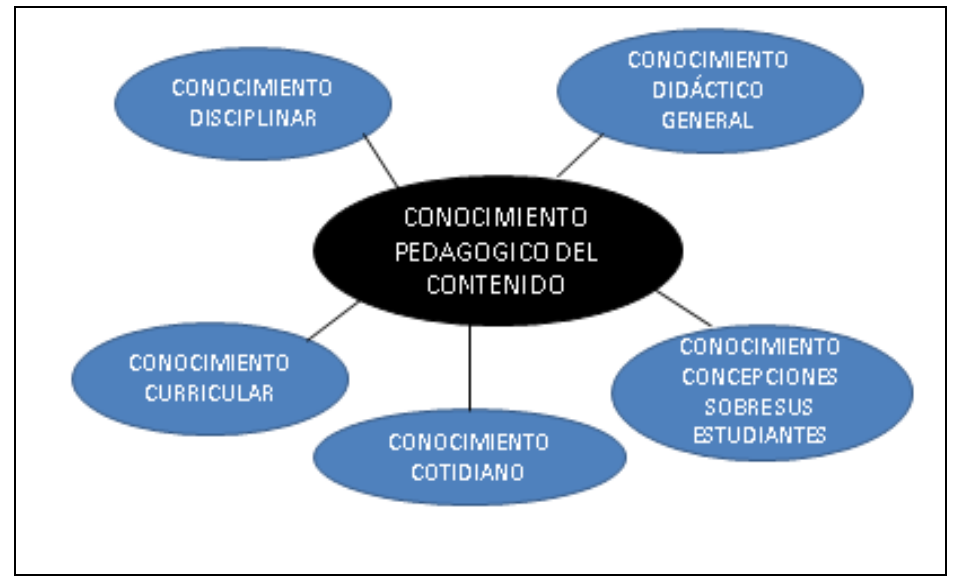


Importante de destacar es que la totalidad del material analizado presenta multiplicidad de modos y medios semióticos combinados para la enseñanza de la ingeniería. Entre ellos podemos mencionar: manipulación de artefactos, presentación de imágenes y simbolismo en power point, además de uso de tablas combinadas con escritura y ejercicios de aplicación matemática, presentados en el medio pizarrón, en las guías de aprendizaje y en diapositivas. Todo esto articulado con gestos deícticos en actividades de trabajo grupal e individual.

\subsection{Estudio de caso 1}

Durante ambas clases, se pudo observar como los gestos son utilizados para dar cohesión y continuidad al flujo de la información. En este caso, en gran parte de su clase el docente mantiene un mismo gesto deíctico sobre zonas particulares del pizarrón en distintos momentos del cálculo matemático, mientras que con el lenguaje oral va introduciendo nueva información conjuntamente.

En el despliegue de los procedimientos a seguir, mediante el habla plantea un mundo abstracto apoyado por gestos que materializan las categorías disciplinares con elementos simbólicos escritos en la pizarra en todas las etapas obligatorias del despliegue. Sobre el uso del pizarrón, se aprecia cómo pone en juego el medio visual el cual es utilizado de manera activa cuando escribe, señala y resuelve los ejercicios de cálculo matemático. Los recursos semióticos para crear significado en este medio son la escritura y el simbolismo matemático. La potencialidad de la pizarra ofrece la doble posibilidad de crear significado, esto es, el docente desarrolla los ejercicios provenientes de las guías de aprendizaje a través de un proceso de resolución mediante colocaciones matemáticas, como se observa en la Imagen 1:

\section{Imagen 1}

Gestos deícticos y producción discursiva

\begin{tabular}{|l|l|l|l|l}
\hline & $\begin{array}{l}(\mathrm{P}) \text { Entonces, cuando estén haciendo estos ejercicios, piensen que } \\
\text { tienen que llegar al resultado, entonces, se van a ver forzados o } \\
\text { motivados, efectivamente, a buscar estas expresiones que son más } \\
\text { manejables algebraicamente. Entonces, sólo para efectos de las } \\
\text { pruebas, en general, yo no les voy a pedir que hagan cálculos } \\
\text { complejos, porque durante las pruebas es pérdida de tiempo. Pero } \\
\text { durante los ejercicios o cuando estén en sus casas, sí tienen que llegar } \\
\text { al resultado. Es la única manera de que Uds. ejerciten este tipo de } \\
\text { trabajo algebraico iPor qué es importante ejercitar el trabajo } \\
\text { algebraico? A diferencia de lo que Uds. hacían en cálculo de álgebra } \\
\text { propiamente tal donde utilizaban propiedades algebraicas, por ejemplo, } \\
\text { productos notables, aquí lo que yo trato de que Uds. ejerciten es } \\
\text { ejercitar, a través de estos trucos, conceptos de probabilidades } \\
\text { (mirando al curso, apuntando al ejercicio) Eso es lo que yo quiero que } \\
\text { Uds. vean. }\end{array}$ \\
\hline
\end{tabular}

Fuente: las imágenes son parte del registro audiovisual realizado en el marco del Proyecto Fondecyt $\mathrm{N}^{\circ} 1130684$

"Alfabetización Semiótica y Mediación en la trayectoria escolar: descripción multimodal de las producciones de los estudiantes y del discurso de los profesores en clases de historia y de biología en una escuela municipalizada". 
En relación con el uso de la guía de ejercicios, si bien este medio participa durante toda la dinámica de sus clases, su potencialidad es distinta. La guía - como un soporte en papel - presenta sólo el encabezado de los ejercicios aún no resueltos. Como se observa en la Figura 3, los recursos presentes en este medio semiótico corresponden esencialmente a escritura y simbolismo matemático:

\section{Figura 3}

Guía de aprendizaje

\section{Gúa Clasel}

1. Un encargado de abastecimiento de una organización recibe dianiamente peticiones de articulos que se utilizan en las diferentes oficinas, y realiza los pedidos a los proveedores una vez a la semana, los dias viennes, demanera que el pedido arniba el lunes a primera hora. La demanda semanal de un cierto cartucho de tinta para impresoras es una y.a. con la siguiente función de probabilidad puntual:

$$
P_{k}=P\{X=k\}=\frac{e^{-j} 3^{k}}{k} \quad k=0,1, \ldots
$$

Sólo la etapa de lectura de las instrucciones de procedimiento de los ejercicios de cálculo matemático presente en las guías de aprendizaje se distingue del resto de las etapas de la clase ya que se enmarca parcialmente en un discurso de tipo cotidiano u horizontal, mientras que el mundo simbólico matemático elaborado en el pizarrón constituye el discurso disciplinar, vertical o también llamado fuera del sentido común (Bernstein, 1999), como se puede leer en la Imagen 2:

\section{Imagen 2}

\section{Uso del pizarrón y producción oral}

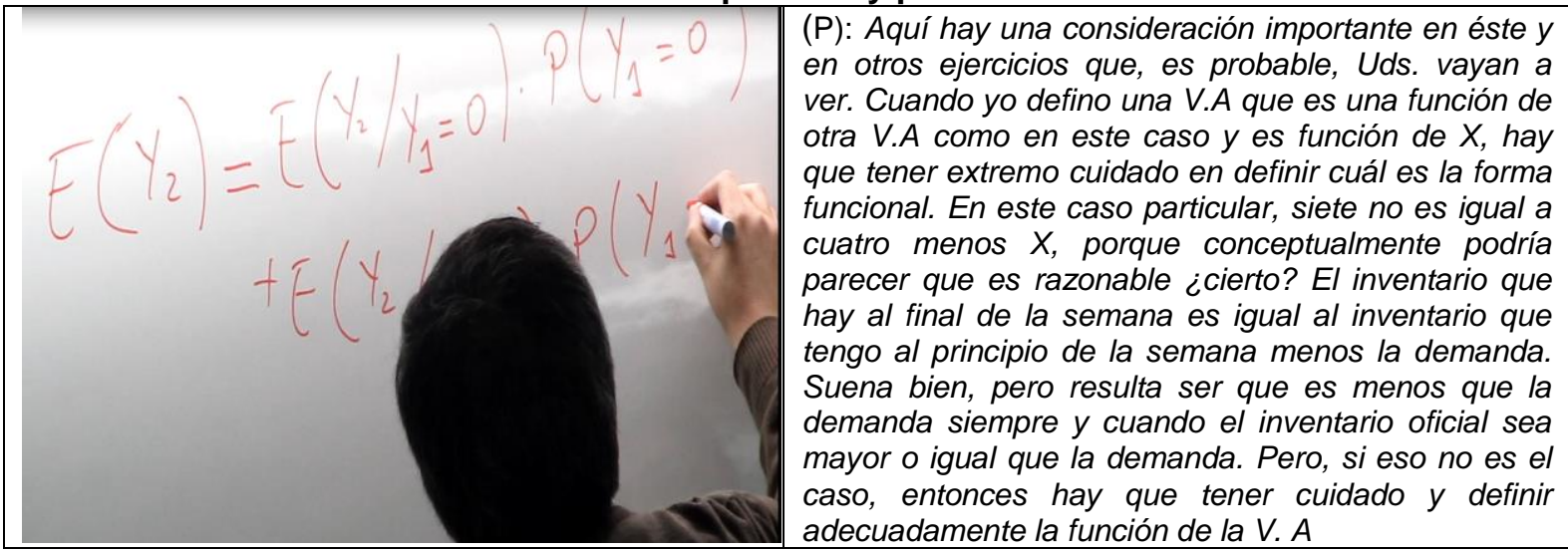

Fuente: las imágenes son parte del registro audiovisual realizado en el marco del Proyecto Fondecyt $\mathrm{N}^{\circ} 1130684$ "Alfabetización Semiótica y Mediación en la trayectoria escolar: descripción multimodal de las producciones de los estudiantes y del discurso de los profesores en clases de historia y de biología en una escuela municipalizada". 
En cuanto a las potencialidades generales de los recursos semiótico-didácticos utilizados por el docente, se aprecian varias diferencias en torno a sus funciones semióticas según el tipo de conocimiento construido por cada recurso; mientras que el simbolismo matemático construye exclusivamente el conocimiento científico mediante entidades abstractas y especializadas (colocaciones numéricas y tablas, por ejemplo), la escritura y la oralidad construyen varios mundos: en menor medida, el mundo cotidiano mediante entidades materiales (personas y objetos reales presentes en situaciones creadas) y, en mayor proporción, el mundo del problema matemático constituido por entidades abstractas, especializadas y metafóricas (partes del problema). De lo observado en este proceso de modelaje de procedimiento de las actividades desarrolladas, las etapas que se reconocen son cinco y se muestran a continuación (Tabla 3):

Tabla 3

Etapas de modelaje del procedimiento

\begin{tabular}{|l|l|l|}
\hline Etapa 1 & Lectura instruccional & $\begin{array}{l}\text { Lectura en voz alta de los encabezados de } \\
\text { los ejercicios por desarrollar, presente en las } \\
\text { guías de trabajo. }\end{array}$ \\
\hline Etapa 2 & $\begin{array}{l}\text { Transcripción } \\
\text { semiótica }\end{array}$ & $\begin{array}{l}\text { El docente modela la traducción desde un } \\
\text { código lingüístico a una combinación } \\
\text { semiótica de simbolismo y lengua. }\end{array}$ \\
\hline Etapa 3 & Escritura notacional & $\begin{array}{l}\text { El docente enfatiza las particularidades de la } \\
\text { combinación semiótica. }\end{array}$ \\
\hline Etapa 4 & $\begin{array}{l}\text { Aplicación } \\
\text { operaciones }\end{array}$ & $\begin{array}{l}\text { El docente desarrolla las transformaciones } \\
\text { que resuelven los ejercicios de cálculo } \\
\text { matemático. }\end{array}$ \\
\hline Etapa 5 & Respuesta & $\begin{array}{l}\text { El docente traduce la respuesta hacia una } \\
\text { representación lingüística. }\end{array}$ \\
\hline
\end{tabular}

Fuente: Elaboración propia.

De este modelaje de procedimiento, se reconocen cuatro mundos representados y comunicados por el docente:

a) Mundo simbólico: cantidades, procesos operacionales, colocaciones;

b) Mundo matemático: cálculo, varianza, valor esperado, probabilidades;

c) Mundo del contexto real: proveedores, inventarios, cartuchos, tintas, impresoras;

d) Mundo del aula: estudiantes, profesor, guías de aprendizaje, pizarra.

De la producción oral en aula, se pudo apreciar un 55,36 \% de discurso disciplinar, un $37,46 \%$ de discurso didáctico general y un 7,18 \% de discurso cotidiano. En lo que se refiere a las concepciones del profesor en torno a la enseñanza y el aprendizaje, el análisis de contenido de la entrevista realizada da cuenta de lo siguiente (ver Tabla 4): 
Tabla 4:

Tipos de conocimientos generados

\begin{tabular}{|c|c|c|}
\hline ategorías & jando se usa & egistro \\
\hline $\begin{array}{l}\text { Conocimiento } \\
\text { disciplinar }\end{array}$ & $\begin{array}{l}\text { Se aplica cuando se } \\
\text { alude a temas, conceptos } \\
\text { o materias propias del } \\
\text { campo disciplinar de la } \\
\text { ingeniería. }\end{array}$ & $\begin{array}{l}\text { "En mis cursos la visión analítica y sistémica es } \\
\text { fundamental, de ahí mi interés por desarrollar esta } \\
\text { parte que es importante trabajar en los } \\
\text { estudiantes". }\end{array}$ \\
\hline $\begin{array}{l}\mathrm{Cc} \\
\mathrm{cu}\end{array}$ & $\begin{array}{l}\text { Se aplica cuando se hace } \\
\text { alusión a patrones y } \\
\text { procesos propios del } \\
\text { currículum: plan de } \\
\text { estudio, perfil de } \\
\text { titulación, mallas, } \\
\text { competencias, etc. }\end{array}$ & $\begin{array}{l}\text { "Los cursos cuantitativos, en general, tienen un } \\
\text { impacto menor sobre las habilidades blandas y un } \\
\text { impacto superior y muy mayor sobre las } \\
\text { habilidades duras, para hacer la diferencia, que son } \\
\text { esencialmente las que están en relación con la } \\
\text { capacidad analítica". }\end{array}$ \\
\hline D & $\begin{array}{l}\text { Se aplica cuando se hace } \\
\text { referencia a: organización } \\
\text { de trabajo en aula, } \\
\text { desarrollo de actividades, } \\
\text { uso de recursos } \\
\text { tecnológico, etc. }\end{array}$ & $\begin{array}{l}\text { "Casi siempre utilizo para efectos de la ejercitación } \\
\text { esta modalidad de quías y solución en pizarra. } \\
\text { Ocasionalmente, para efectos de ahorrar tiempo, } \\
\text { proyecto las soluciones que están resueltas de } \\
\text { antes". }\end{array}$ \\
\hline $\begin{array}{ll}\text { Conocimiento } & \\
\text { sobre } & \text { los } \\
\text { estudiantes } & \end{array}$ & $\begin{array}{l}\text { Se aplica cuando se } \\
\text { refiere a las concepciones } \\
\text { sobre las características } \\
\text { particulares de los } \\
\text { estudiantes. }\end{array}$ & $\begin{array}{l}\text { "Si tú me preguntas si considero origen geográfico } \\
\text { de mis alumnos en la planificación de mis } \\
\text { actividades, mi respuesta es no. Tú me dices si yo } \\
\text { considero nivel socioeconómico, mi respuesta es } \\
\text { no. A priori, yo diría que no tengo consideraciones } \\
\text { que me permitan adaptar el programa del curso a } \\
\text { esos factores". }\end{array}$ \\
\hline $\begin{array}{l}\text { Cor } \\
\text { coti }\end{array}$ & $\begin{array}{lrr}\text { Se aplica } & \text { cuando se } \\
\text { vinculan } & \text { situaciones } \\
\text { cotidianas } & 0 \\
\text { pertenecientes } & \text { a } \\
\text { contextos reales. } & \\
\end{array}$ & $\begin{array}{l}\text { "Los ejemplos y los tipos de ejercicios que se dan } \\
\text { están mucho más vinculados a problemas } \\
\text { puntuales, simplificaciones que se necesitan, pero } \\
\text { yo diría a problemas que tienen sentido en el } \\
\text { contexto real". }\end{array}$ \\
\hline
\end{tabular}

Fuente: Basada en MacQueen, McLellan, Kay y Milstein, 1998.

Como se ha podido observar, se desprende que el tipo de conocimiento generado por el docente se construye con predominancia en lo disciplinar, centrado en el desarrollo de la visión sistémica y la capacidad analítica. En síntesis, habilidades duras.

\subsection{Estudio de caso 2}

En este caso, las prácticas docentes giran principalmente en torno a los recursos del habla, gestos, presentación de videos y exposición en PowerPoint (Imagen 3). La puesta en marcha de los elementos anteriores se articula siempre proyectando las actividades de trabajo colaborativo, lo cual posibilita una mayor interacción dialógica profesora alumno/alumna. 


\section{Imagen 3}

Uso de PowerPoint y producción discursiva

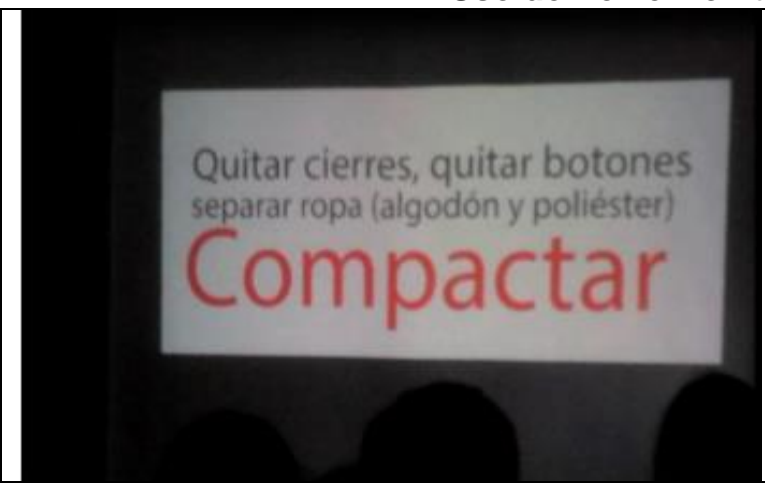

(P) El método Scamper busca modificar el problema, cuestionarse qué pasa si cambio algo de este problema, cómo afrontamos las posibles soluciones. Un ejemplo: cuando pensamos en el problema de amplificar, podemos imaginarnos no solo en meter harta ropa, o sea, "un cerro de ropa". Así, cuando amplificamos, lo que estamos modificando no es la solución, sino el problema que afrontaremos. ¿Qué se imaginaron ustedes? sobre cómo abordar este "cerro de ropa"?

(A) Que debíamos clasificarla como solución

$(P)$ Lo importante es no quedarnos en una solución, sino seguir avanzando hacia otras más. De este modo, se nos van ocurriendo otras muchas ideas.

Fuente: las imágenes son parte del registro audiovisual realizado en el marco del Proyecto Fondecyt №1130684 "Alfabetización Semiótica y Mediación en la trayectoria escolar: descripción multimodal de las producciones de los estudiantes y del discurso de los profesores en clases de historia y de biología en una escuela municipalizada".

En relación con el desarrollo de las ATA, se aprecia cómo el despliegue del metadiscurso en el análisis de razonamiento se caracteriza por la coutilización de gestos, ejemplificación oral, uso de imágenes y manipulación de artefactos materiales (ver Imagen 4). En el despliegue de los procedimientos por seguir, la profesora propone un trabajo mayormente de producción, el cual es apoyado por gestos que materializan las categorías disciplinares vinculadas con contenidos conceptuales presentados en diapositivas en todas las etapas obligatorias previas al despliegue de las actividades de trabajo grupal.

Imagen 4

Manipulación de artefactos materiales

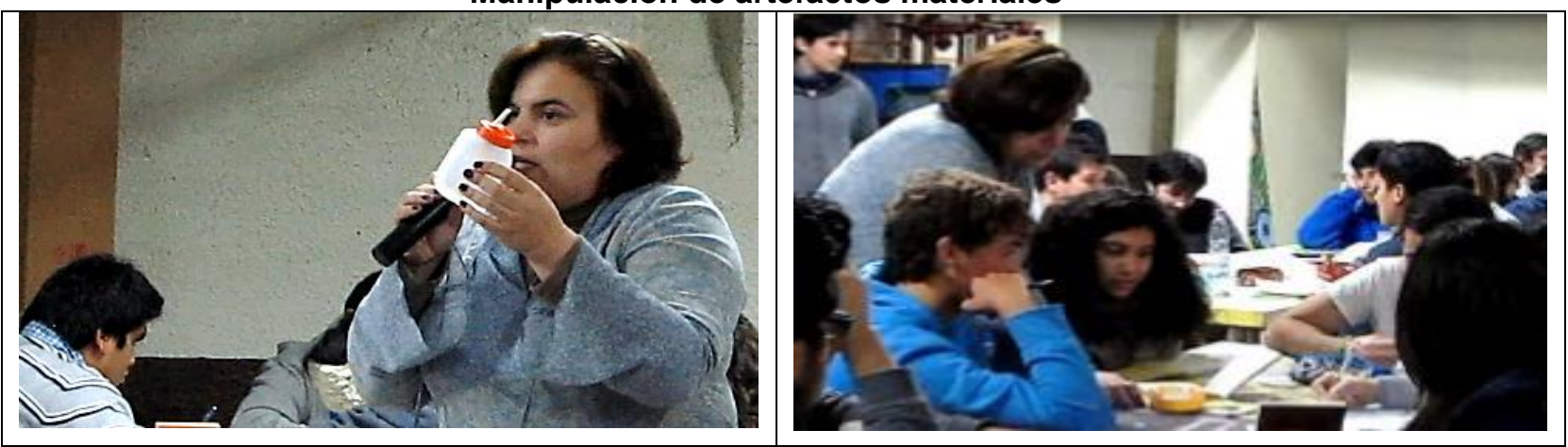

Fuente: las imágenes son parte del registro audiovisual realizado en el marco del Proyecto Fondecyt №1130684 "Alfabetización Semiótica y Mediación en la trayectoria escolar: descripción multimodal de las producciones de los estudiantes y del discurso de los profesores en clases de historia y de biología en una escuela municipalizada".

Sobre las potencialidades de los recursos semióticos utilizados, se observan varias diferencias entre las funciones semióticas del lenguaje, relacionadas con el tipo de conocimiento construido por cada recurso y las actividades desplegadas. Mientras que el trabajo de escritura colaborativa apunta hacia la aplicación disciplinar del objeto 
epistemológico mediante la movilización de entidades y conceptualizaciones especializadas aplicadas a la elaboración de un producto; la oralidad y la escritura, por su parte, van construyendo diferentes tipos de conocimiento simultáneamente: conocimiento cotidiano mediante entidades materiales (personas, hechos y objetos provenientes del contexto real, presentados a modo de ejemplo) y conocimiento científico disciplinar asociado a la creatividad y la innovación mediante la mixtura de conceptualizaciones, entidades abstractas, concretas y especializadas.

De lo observado en este proceso de modelaje de procedimiento de las actividades desplegadas, las etapas que se reconocen son cinco y se muestran a continuación (ver Tabla 5):

Tabla 5

Etapas de modelaje del procedimiento

\begin{tabular}{|c|c|c|}
\hline Etapa 1 & $\begin{array}{l}\text { Declaración } \\
\text { instruccional }\end{array}$ & $\begin{array}{l}\text { La académica oraliza las instrucciones en } \\
\text { torno a las tareas individuales y colectivas } \\
\text { que se desarrollan en la clase. }\end{array}$ \\
\hline Etapa 2 & $\begin{array}{l}\text { Transcripción } \\
\text { semiótica }\end{array}$ & $\begin{array}{l}\text { La profesora modela la traducción desde un } \\
\text { código visual - lingüístico a una combinación } \\
\text { semiótica de lengua y gestos. }\end{array}$ \\
\hline Etapa 3 & Ejemplificación & $\begin{array}{l}\text { La académica enfatiza las particularidades } \\
\text { de la combinación semiótica. }\end{array}$ \\
\hline Etapa 4 & $\begin{array}{l}\text { Aplicación } \\
\text { operaciones }\end{array}$ & $\begin{array}{l}\text { Los alumnos desarrollan las actividades } \\
\text { propuestas por la docente quien media en el } \\
\text { trabajo individual y colectivo. }\end{array}$ \\
\hline Etapa 5 & Respuesta & $\begin{array}{l}\text { La profesora traduce lo realizado por el } \\
\text { curso hacia una representación lingüística. }\end{array}$ \\
\hline
\end{tabular}

Fuente: Elaboración propia.

De este modelaje de procedimiento, se reconocen cuatro mundos representados y comunicados por la profesora:

a) Mundo simbólico: objeto aleatorio, radical, eje central;

b) Mundo de la creatividad: método Scamper, pensamiento divergente;

c) Mundo del contexto real: ropa, damnificados, incendio, ciudad de Valparaíso;

d) Mundo del aula: estudiantes, profesora, PowerPoint, micrófono, videos, artefactos materiales.

De la producción oral en aula se observa que un 21,94 \% corresponde a discurso disciplinar, un 35,08 \% corresponde a discurso didáctico general y un 42,98 \% corresponde a discurso cotidiano. En lo que respecta a las concepciones en torno a la enseñanza y el aprendizaje, el análisis de contenido de la entrevista realizada nos da cuenta de lo siguiente (ver Tabla 6): 
Tabla 6

Tipos de conocimientos generados

\begin{tabular}{|c|c|c|}
\hline Categorías & Cuando se usa & Ejemplo de registro \\
\hline $\begin{array}{l}\text { Conocimiento } \\
\text { disciplinar }\end{array}$ & $\begin{array}{l}\text { Se aplica cuando se alude a } \\
\text { temas, conceptos o materias } \\
\text { propias del campo de la } \\
\text { ingeniería. }\end{array}$ & $\begin{array}{l}\text { "El gran peso de este curso es que es un } \\
\text { curso de creatividad, por ende, si nosotros } \\
\text { no somos creativos en diseñar actividades, } \\
\text { entonces, predicamos mal nuestro ejemplo". }\end{array}$ \\
\hline $\begin{array}{l}\text { Conocimiento } \\
\text { curricular }\end{array}$ & $\begin{array}{l}\text { Se aplica cuando se hace } \\
\text { alusión a patrones y procesos } \\
\text { propios del currículum: plan de } \\
\text { estudio, perfil de titulación, } \\
\text { mallas, competencias, etc. }\end{array}$ & $\begin{array}{l}\text { "Finalmente, la capacidad de creatividad, } \\
\text { innovación y emprendimiento constituyen la } \\
\text { línea que desarrollamos en nuestro nuevo } \\
\text { plan de estudios". }\end{array}$ \\
\hline $\begin{array}{l}\text { Conocimiento } \\
\text { didáctico general }\end{array}$ & $\begin{array}{l}\text { Se aplica cuando se hace } \\
\text { referencia a: organización de } \\
\text { trabajo en aula, desarrollo de } \\
\text { actividades, uso de recursos } \\
\text { tecnológico, etc. }\end{array}$ & $\begin{array}{l}\text { "El propósito que tenemos en este curso es } \\
\text { que el alumno no tenga que estudiar estas } \\
\text { materias, lo importante es que las tenga que } \\
\text { vivenciar, la vivencia de que él aprenda } \\
\text { porque hizo algo, eso es lo que él recuerda". }\end{array}$ \\
\hline $\begin{array}{l}\text { Conocimiento } \\
\text { sobre } \\
\text { estudiantes }\end{array}$ & \begin{tabular}{l}
\multicolumn{3}{l}{ Se aplica cuando se refiere a las } \\
concepciones sobre $r$ las \\
características particulares de \\
los estudiantes.
\end{tabular} & $\begin{array}{l}\text { "Nosotros a través de preguntas acerca de } \\
\text { sus talentos, por ejemplo, les preguntamos } \\
\text { en una clase sobre eso para que a la } \\
\text { siguiente podamos armar los grupos en } \\
\text { función de eso y puedan quedar mezclados". }\end{array}$ \\
\hline $\begin{array}{l}\text { Conocimiento } \\
\text { cotidiano }\end{array}$ & $\begin{array}{l}\text { Se aplica cuando se vinculan } \\
\text { situaciones } \\
\text { pertenecientes } \\
\text { reales. }\end{array}$ & $\begin{array}{l}\text { "Una de las cosas que hacemos siempre es } \\
\text { mostrarles a los alumnos avisos del periódico } \\
\text { en que se buscan ingenieros industriales } \\
\text { donde listan en los requerimientos que una } \\
\text { de las habilidades que necesitan poseer es } \\
\text { la habilidad creativa". }\end{array}$ \\
\hline
\end{tabular}

Fuente: Basada en MacQueen, McLellan, Kay y Milstein, 1998.

Como se observa, existe una predominancia al desarrollo de la creatividad a través de un trabajo procedimental y colaborativo observado tanto en su despliegue de las ATAs, como también en sus concepciones sobre su propia práctica de enseñanza.

\subsection{Estudio de caso 3}

Las prácticas docentes en este caso giran en torno al despliegue de los recursos semióticos del habla, los gestos, el simbolismo matemático y la escritura. En relación con el uso específico de la pizarra y del PowerPoint, la acción central de la sala de clases se lleva a cabo en torno a estos recursos tecnológicos. Sobre la interacción cara a cara, es posible señalar que esta depende en gran medida del proceso de desarrollo del problema matemático presentado en el pizarrón y en PowerPoint (Imagen 5). 


\section{Imagen 5}

\section{Gesto deíctico y producción oral}

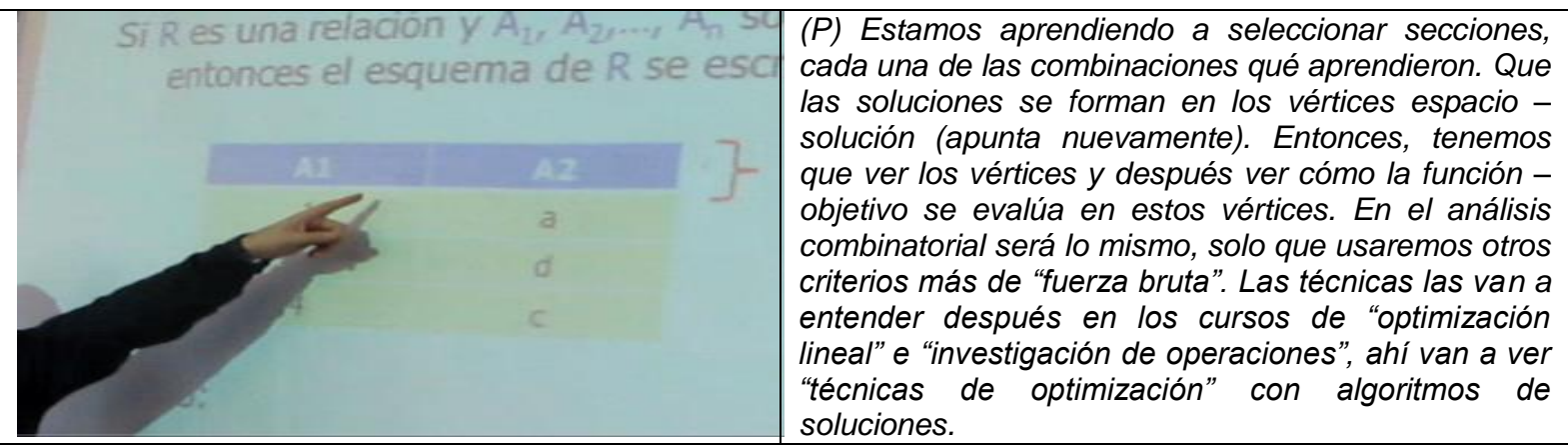

Fuente: las imágenes son parte del registro audiovisual realizado en el marco del Proyecto Fondecyt №1130684 "Alfabetización Semiótica y Mediación en la trayectoria escolar: descripción multimodal de las producciones de los estudiantes y del discurso de los profesores en clases de historia y de biología en una escuela municipalizada".

La potencialidad del PowerPoint y la pizarra conjuntamente ofrecen la doble posibilidad de crear significado en forma dinámica, esto es, se analizan los ejercicios presentes en las diapositivas (Imagen 6) mediante un proceso de resolución en el pizarrón.

\section{Imagen 6}

Proyección digital y producción oral

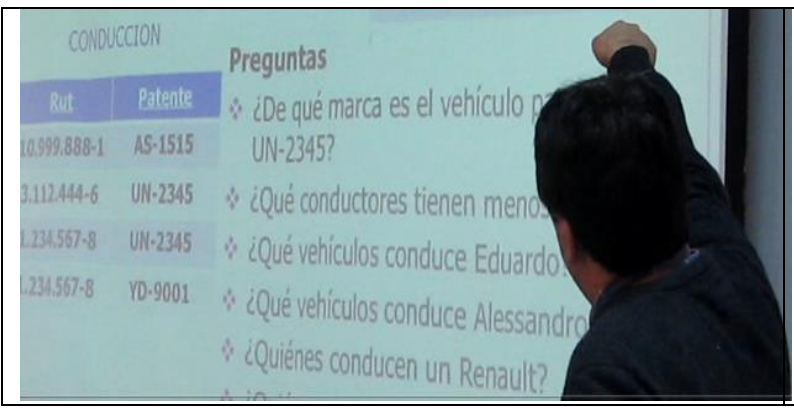

$(P)$ Supongamos lo siguiente: tenemos una base de datos de un registro de conductores, nosotros tenemos el Rut, el nombre y la edad. Por lo tanto, estos son dominios y el conductor es una relación que en su conjunto reúne todos estos elementos. Por otra parte, tenemos la entidad - vehículo que también es una tabla, también es una relación y en su conjunto: Rut - patente - marca. Esa es la información que tenemos guardada en la base de datos de conductores de una institución ¿Cómo vamos hasta ahí? (cambia de diapositiva).

Fuente: las imágenes son parte del registro audiovisual realizado en el marco del Proyecto Fondecyt $\mathrm{N}^{\circ} 1130684$ "Alfabetización Semiótica y Mediación en la trayectoria escolar: descripción multimodal de las producciones de los estudiantes y del discurso de los profesores en clases de historia y de biología en una escuela municipalizada".

En gran parte de su clase, el docente usa el medio pizarrón desplegando simbolismo y, menos frecuente, escritura. Conjuntamente, emplea gestos deícticos principalmente en etapas particulares del despliegue de las ATAs a las cuales hemos denominado como "escritura notacional" (Manghi, 2013, p. 214). En esta etapa, el pizarrón juega un rol importante en la construcción de significados (ver Imagen 7) pero, a diferencia de otras etapas, es usado acá para indicar elementos ya desplegados previamente desde otros medios semióticos, como son el power point o la guía de aprendizaje. 
Imagen 7

Uso del pizarrón

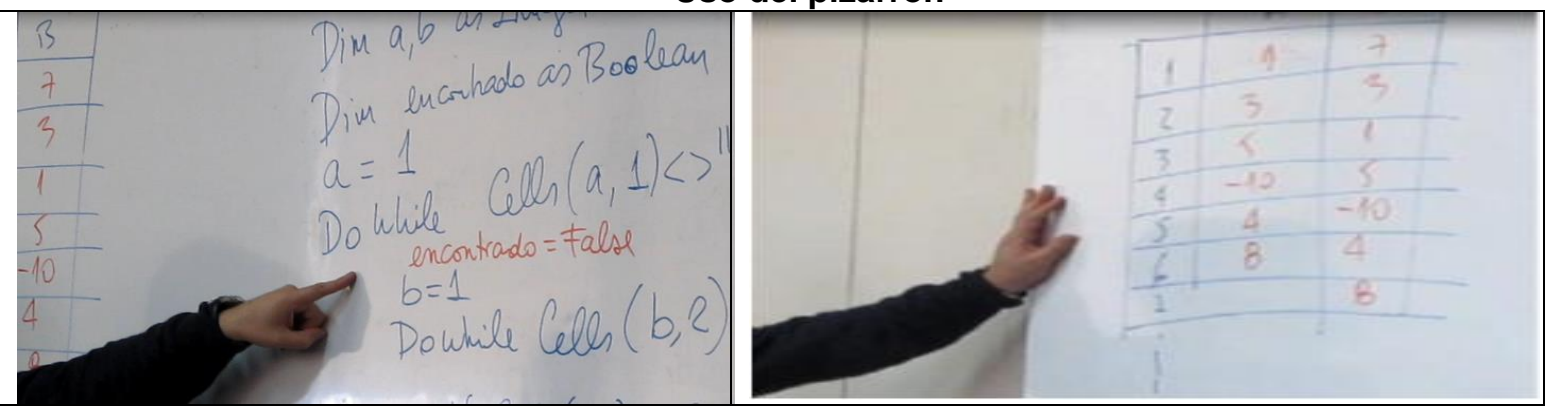

Fuente: las imágenes son parte del registro audiovisual realizado en el marco del Proyecto Fondecyt $\mathrm{N}^{\circ} 1130684$ "Alfabetización Semiótica y Mediación en la trayectoria escolar: descripción multimodal de las producciones de los estudiantes y del discurso de los profesores en clases de historia y de biología en una escuela municipalizada".

En cuanto al uso de la guía de aprendizaje, si bien este medio participa durante toda la dinámica de clase, su potencialidad es distinta. La guía de aprendizaje se presenta como un producto en soporte papel, lo cual afecta tanto los modos para significar, así como las acciones semióticas puestas en juego. Como se observa en la Figura 4, los modos semióticos presentes en el formato guía corresponden esencialmente a simbolismo matemático y escritura:

Figura 4

Guía de aprendizaje

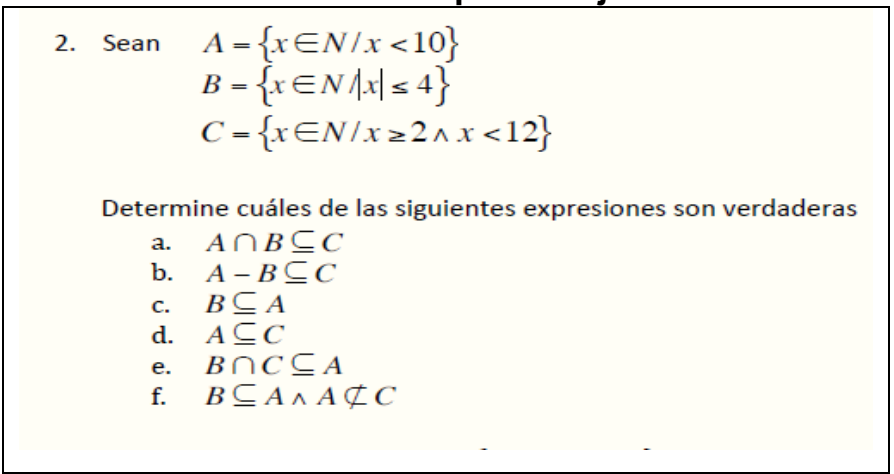

En relación con las potencialidades de los recursos semiótico-didácticos utilizados, se observan algunas diferencias en relación con el tipo de conocimiento construido: mientras que en la pizarra se construye exclusivamente el mundo científico-matemático mediante entidades especializadas (colocaciones numéricas, por ejemplo), en PowerPoint se construye de modo interactivo el mundo matemático compuesto de entidades abstractas, simbólicas, metafóricas, especializadas, y también entidades del mundo cotidiano (ver Imagen 6), aunque estas en menor medida. 
Conjuntamente a través del habla se va articulando conocimiento científico y cotidiano mediante entidades conceptuales, materiales y ejemplos provenientes de la vida diaria (personas y objetos reales) con el fin de hacer aplicable los contenidos conceptuales puestos en juego a través de los recursos tecnológicos utilizados. De lo observado en este proceso de modelaje de procedimiento de las actividades desarrolladas, las etapas que se reconocen son cinco y se muestran a continuación (ver Tabla 7):

Tabla 7

Etapas de modelaje del procedimiento

\begin{tabular}{|l|l|l|}
\hline Etapa 1 & Lectura instruccional & $\begin{array}{l}\text { Lectura en voz alta de los encabezados de } \\
\text { los ejercicios por desarrollar, presentes en } \\
\text { las guías de trabajo o en las diapositivas } \\
\text { proyectadas en PowerPoint. }\end{array}$ \\
\hline Etapa 2 & $\begin{array}{l}\text { Transcripción } \\
\text { semiótica }\end{array}$ & $\begin{array}{l}\text { El docente modela la traducción desde } \\
\text { código lingüístico a una combinación } \\
\text { semiótica de simbolismo y lengua. }\end{array}$ \\
\hline Etapa 3 & Escritura notacional & $\begin{array}{l}\text { El académico enfatiza las particularidades de } \\
\text { la combinación semiótica usando pizarrón. }\end{array}$ \\
\hline Etapa 4 & $\begin{array}{l}\text { Aplicación } \\
\text { operaciones }\end{array}$ & $\begin{array}{l}\text { El docente desarrolla las transformaciones } \\
\text { que resuelven los problemas de tipo } \\
\text { matemático. }\end{array}$ \\
\hline Etapa 5 & Respuesta & $\begin{array}{l}\text { El académico traduce la respuesta hacia una } \\
\text { representación lingüística. }\end{array}$ \\
\hline
\end{tabular}

Fuente: Elaboración propia.

De este modelaje de procedimiento, se reconocen cuatro mundos representados y comunicados por el docente:

a) Mundo simbólico: colocaciones, códigos, conjuntos por extensión;

b) Mundo matemático: teoría de conjuntos, álgebra, modelo relacional;

c) Mundo del contexto real: patentes, consumidores, conductores, supermercados;

d) Mundo del aula: estudiantes, profesor, guías de aprendizaje, pizarra, PowerPoint.

Sobre la producción oral en el aula, un 53,37 \% corresponde a discurso disciplinar, un $31,70 \%$ a discurso didáctico general y un $14,93 \%$ a discurso cotidiano.

En lo que se refiere a las concepciones pedagógicas del académico en torno a la enseñanza y el aprendizaje, el análisis de contenido realizado sobre la entrevista da cuenta de lo siguiente (ver Tabla 8): 
Tabla 8

Tipos de conocimientos generados

\begin{tabular}{|c|c|c|}
\hline Categorías & Cuando se usa & Ejemplo de registro \\
\hline $\begin{array}{l}\text { Conocimient } \\
\text { o disciplinar }\end{array}$ & $\begin{array}{l}\text { Se aplica cuando se alude a } \\
\text { temas, conceptos o materias } \\
\text { propias del campo de la } \\
\text { ingeniería. }\end{array}$ & $\begin{array}{l}\text { Yo espero que se entienda la base del concepto y } \\
\text { que después ellos, con el estudio, a través de la } \\
\text { ejercitación o de lectura adicional puedan } \\
\text { entender y aplicar a cabalidad el concepto. } \\
\text { Nosotros en ingeniería, el aprendizaje lo } \\
\text { traducimos en aplicación". }\end{array}$ \\
\hline $\begin{array}{l}\text { Conocimient } \\
\text { o curricular }\end{array}$ & $\begin{array}{l}\text { Se aplica cuando se hace } \\
\text { alusión a patrones y procesos } \\
\text { propios del currículum: plan } \\
\text { de estudio, perfil de titulación, } \\
\text { mallas, competencias, etc. }\end{array}$ & $\begin{array}{l}\text { "El curso de 'Modelamiento Discreto' tiene que } \\
\text { ver con el desarrollo de la capacidad analítica, } \\
\text { tiene que estar por aquí (apuntando al perfil de } \\
\text { titulación), un poco de ciencias básicas y } \\
\text { capacidad analítica". }\end{array}$ \\
\hline $\begin{array}{l}\text { Conocimient } \\
\text { o didáctico } \\
\text { general }\end{array}$ & $\begin{array}{l}\text { Se aplica cuando se hace } \\
\text { referencia a: organización de } \\
\text { trabajo en aula, desarrollo de } \\
\text { actividades, uso de recursos } \\
\text { tecnológico, etc. }\end{array}$ & $\begin{array}{l}\text { "El PowerPoint me sirve para estructurar la } \\
\text { presentación de los conceptos, porque en el } \\
\text { PowerPoint tengo definido los conceptos de la } \\
\text { mayoría de mis asignaturas, hilo conductor y } \\
\text { ejemplos. Pero después, cuando hay que } \\
\text { ejercitar, cuando hay que aplicar uso la pizarra". }\end{array}$ \\
\hline $\begin{array}{l}\text { Conocimient } \\
\text { o sobre los } \\
\text { estudiantes }\end{array}$ & $\begin{array}{l}\text { Se aplica cuando se refiere a } \\
\text { las concepciones sobre las } \\
\text { características particulares de } \\
\text { los estudiantes }\end{array}$ & $\begin{array}{l}\text { "Cuando nosotros tenemos cursos de setenta } \\
\text { alumnos en una clase u otros paralelos de ciento } \\
\text { ochenta alumnos es muy difícil atender } \\
\text { situaciones particulares pensando en eso, sino } \\
\text { que de alguna forma tenemos que verlas por } \\
\text { otros lados, ya sea a nivel de jefatura de } \\
\text { docencia, pero no directamente en el aula. No } \frac{\text { No }}{\text { tengo una planificación especial atendiendo a las }} \\
\text { necesidades individuales de cada alumno en la } \\
\text { sala de clases". }\end{array}$ \\
\hline $\begin{array}{l}\text { Conocimient } \\
\text { o cotidiano }\end{array}$ & $\begin{array}{l}\text { Se aplica cuando se vinculan } \\
\text { situaciones cotidianas o } \\
\text { pertenecientes a contextos } \\
\text { reales }\end{array}$ & $\begin{array}{l}\text { "Mi curso de 'Modelamiento Discreto' es } \\
\text { básicamente ciencia, matemática discreta, } \\
\text { programación, entonces, no hay tanto espacio } \\
\text { para introducir otros elementos". }\end{array}$ \\
\hline
\end{tabular}

Fuente: Basada en MacQueen, McLellan, Kay y Milstein, 1998.

Se desprende que las concepciones pedagógicas del entrevistado, como el despliegue de sus actividades típicas de aula, estarían centradas predominantemente en el desarrollo de la capacidad analítica y la aplicación, aspectos medulares de su disciplina.

\section{Conclusiones finales}

El enfoque elegido para esta investigación permite preguntar sobre la funcionalidad de los distintos medios y modos semióticos desplegados por estos docentes en la sala de clases. Como se ha observado, los significados construidos por estos tres académicos en sus respectivos contextos de aula están entretejidos por la combinación diversificada de artefactos y recursos semióticos desplegados para la enseñanza. Las semejanzas entre los docentes se dan en su puesta en juego mediante la articulación en combinatoria de lengua 
oral, escritura y simbolismo. Las diferencias incluyen una etapa genérica que requiere del uso particular de distintos formatos de imágenes y artefactos materiales en momentos determinados de la clase. Esta es la etapa que refleja un andamiaje explícito de los tres académicos acerca de las formas en que esperan que sus aprendices asimilen y representen el conocimiento disciplinar aprendido.

Esta exploración en torno al conocimiento pedagógico del contenido observado en tres docentes ingenieros a través del análisis multimodal del discurso devela que los académicos estudiados (re) construyen un discurso de aula marcado por el conocimiento disciplinar que enseñan, por ello, los distintos medios y modos semióticos que combinan con el fin de que sus aprendices aprendan a razonar y comunicarse varían unos de otros, de manera particular, según la materia que se produce. En este caso pertinente, los docentes reproducen en la sala de clases, principalmente, aquellas maneras especiales de representar y comunicar los conocimientos específicos de su disciplina o materia particular (Bernstein, 2000). En sintonía con Shulman (1999; 2004), se propone que los docentes debieran poner especial foco de atención no solo en la transmisión de los conocimientos propios de su área de estudio, sino también en la integración de los demás tipos de conocimientos dado que la enseñanza de una profesión necesita de un equilibrio en la movilización de los saberes pedagógicos necesarios para la transferencia y aplicación en las tareas de desempeño.

Para autores como Vosniadou (1994), si bien los aprendizajes provenientes de las vinculaciones entre conocimiento cotidiano y científico son incompatibles dada la independencia y autonomía de uno y otro, para nuestros fines, ambas dimensiones estarían innegablemente interconectadas unas con otras dado que vendrían a posibilitar mayores opciones de enseñanza en los docentes y mayores posibilidades de aprendizaje en los estudiantes. De este modo, este tipo de vinculación vendría a funcionar como un potente mediador en la adquisición y comprensión de nuevos conocimientos científicos (Vygotsky, 1987) en quienes se forman en la educación superior.

En concordancia con la propuesta de Moss y Chamorro (2008), se postula que algunas formas de representación y comunicación de los conocimientos científicos están alejadas del conocimiento cotidiano o de sentido común de los aprendices, convirtiéndose esto muchas veces en un obstáculo para el aprendizaje. Esto requiere que los docentes acerquen a sus estudiantes a las especificidades de estos discursos y conocimientos tanto disciplinares como cotidianos de manera articulada. Es por lo anterior que la formación de profesionales a nivel universitario, incluidos los ingenieros, convendría darse apoyada en distintas 
heurísticas, lo que implica no aferrarse dogmáticamente a determinados recursos y métodos provenientes del mundo científico (García, 2014).

En la enseñanza de la ingeniería, ciencia, lenguaje y experiencia son tres dimensiones intrínsecas e inseparables (Maton, 2014), ya que enseñar ciencia exige aprender a observar y a representar, de múltiples formas, los fenómenos particulares de un objeto de estudio. Poniendo énfasis en la necesidad de considerar estos fenómenos de forma integrada, se plantea la importancia de vincular en el aula las demandas del entorno natural y social como parte del desarrollo integral del aprendiz, por lo cual, se propone organizar la enseñanza mediante el desarrollo de habilidades que otorguen respuestas y soluciones a las problemáticas del mundo experiencial y profesional en su conjunto (García, 2014).

Frente a esto, la perspectiva multimodal de la enseñanza entrega valiosas herramientas pedagógicas mediante el uso de múltiples representaciones conceptuales, lo cual, se traduce en la actualidad en una potente estrategia de mediación y transmisión de conocimiento científico (Lemke, 2008) para quienes imparten docencia en educación superior. Cabe destacar el rol de la mirada multimodal del discurso con fines educativos la cual abre nuevas preguntas acerca de los discursos y los formatos didácticos articulados en el aula, así como la alfabetización semiótica y su mediación en la educación superior. En la presente investigación, se evidencia que el análisis multimodal permite no solo la descripción, sino también la interpretación de las opciones, funciones y usos de los recursos y artefactos semióticos desplegados en el salón de clases.

Este estudio en torno al conocimiento pedagógico del contenido desde un enfoque multimodal debiera abrir nuevos espacios reflexivos sobre mediación semiótica en profesores universitarios que no poseen estudios formales en pedagogía, pero que están interesados en articular un despliegue pedagógico reflexivo, intencionado y críticamente fundamentado en el aula. Si bien consideramos el discurso pedagógico como una dinámica en constante movimiento y construcción, no deja de ser valorable la categorización de dimensiones de conocimiento propuesta por Shullman (1987) como una metodología clara y facilitadora de investigación para quienes desean estudiar los vacíos y problemáticas pedagógicas de la formación académica en educación superior. En este sentido, diversas investigaciones dejan de manifiesto que la reflexión teórico-práctica de la enseñanza en torno a la convergencia de saberes disciplinares y pedagógicos puede impactar de forma significativa en la formación continua de quienes imparten docencia (Abell, 2008; Loughran, Berry y Mulhall, 2012). 
Entre las proyecciones establecidas para una nueva investigación de estas características se propone la idea de incluir, como población de estudio, una muestra conformada por profesores y estudiantes universitarios con el fin de sumar al trabajo metodológico un análisis sobre las estrategias de enseñanza y aprendizaje con el propósito de vincular y contrastar los procesos de transmisión y asimilación del conocimiento de estos dos actores educativos. Conjuntamente, se valora la idea de levantar un número mayor de registros audiovisuales de un conjunto mayor de clases y así poder analizar unidades de estudio completas. Esto permitiría obtener una mirada más global del aula y de los procesos de construcción de significados generados en ese contexto educativo particular.

Por último, los resultados de este estudio de casos múltiple, si bien no son generalizables, pueden iluminar la formación continua de docentes que no tienen formación en pedagogía, pero interesados en querer potenciar, de manera reflexiva, sus herramientas pedagógicas en torno a la enseñanza y el aprendizaje del lenguaje de las ciencias.

\section{Referencias}

Abell, Sandra. (2008). Twenty years later: does pedagogical content knowledge remain a useful idea? International Journal of Science Education, 30(10), 1405-1416. Recuperado http://fplfachdidaktik.univie.ac.at/fileadmin/fronter/Ressourcen/Literatur/Abel 20 years $\underline{\text { later.pdf }}$

Badillo, Carolina, Córdova, Juan Pablo, Manghi, Dominique y Haas, Valentina. (2 de agosto, 2013). Cine, fotografía, caricaturas, mapas y ipor qué no? pizarrón. Potencial semiótico y orquestación de recursos para la enseñanza (Proyecto Fondecyt N¹130684 "Alfabetización semiótica y mediación en la trayectoria escolar"). Ponencia presentada en Congreso Internacional de Creatividad e Innovación, Concepción Chile.

Baldry, Anthony y Thibault, Paul. (2006). Multimodal Transcription and Text Analysis. A multimedia toolkit and coursebook with associated on-line course. Oakville, London: Equinox Textbooks and Survey in Linguistics.

Bernstein, Basil. (1999). Vertical and horizontal discourse: an essay. British Journal of Sociology of Education, 20(2), 157-173.

Bernstein, Basil. (2000). Pedagogy, symbolic control and identity: theory, research, critique. London: Taylor y Francis.

Brunner, José Joaquín. (2008). El proceso de Bolonia en el horizonte latinoamericano: límites y posibilidades. Revista de Educación, (Extraordinario). Recuperado de http://www.revistaeducacion.mec.es/re2008/re2008 06.pdf 
Cáceres, Pablo. (2003). Análisis cualitativo de contenido: una alternativa metodológica alcanzable. Psicoperspectivas, 2, 53-82. Recuperado de http://psicoperspectivas.cl/index.php/psicoperspectivas/article/viewFile/3/3

Córdova, Juan Pablo, Melo, Giselle, Bacigalupo, Francesca y Manghi, Dominique. (2016). Olas de significado en la interacción profesor-alumno: análisis de dos clases de Ciencias Naturales de un 6to de primaria. Ciência \& Educação (Bauru), 22(2), 335-350. Recuperado de http://www.redalyc.org/pdf/2510/251046221005.pdf

Denzin, Norman y Lincoln, Yvonna. (2012). Manual de investigación cualitativa (Vol.1: El campo de la investigación cualitativa). Barcelona, España: Editorial Gedisa.

Farías, Miguel y Araya, Claudio. (2014). Alfabetización visual crítica y educación en lengua materna: estrategias metacognitivas en la comprensión lectora de textos multimodales. Colombian Applied Linguistics Journal, 16(1), 93-104.

Farías, Miguel y Araya, Claudio. (2015). Hacia una caracterización de los textos multimodales usados en formación inicial docente en lenguaje y comunicación. Revista Literatura y lingüística, (32), 283-304.

Gaitán, Carlos y Jaramillo, Juliana. (2007). Formación Docente en la Educación Superior. Modelo Educativo para la Formación Pedagógico-Didáctica. Colombia: Editorial Pontificia Universidad Javeriana.

García, José Ángel. (2014). Ingeniería, Matemáticas y Competencias. Revista Electrónica Actualidades Investigativas en Educación, 14(1), 1-29. Recuperado de http://www.revistas.ucr.ac.cr/index.php/aie/article/view/13383/12650

Hall, Beatriz y López, María Isabel. (2011). Discurso académico: manuales universitarios y prácticas pedagógicas. Revista Literatura y Lingüística, (23), 167-192. Recuperado de http://www.scielo.cl/scielo.php?script=sci arttext\&pid=S0716-58112011000100010

Halliday, Michael. (1979). El lenguaje como semiótica social. México: Fondo de Cultura Económica.

Hodge, Robert y Kress, Gunther. (1988). Social Semiotics. Cambridge: Polity Press.

Hood, Susan. (2009). Embodying language. En Dreyfus Shoshana, Susan Hood y Marre Stenglin (Eds.), Semiotic Margins. Meaning in multimodalities (pp. 34-48). Londres: Equinox.

Imbernon, Francesc. (2005). Vivencias de maestros y maestras. Compartir desde la práctica educativa. Barcelona: Grao.

Irigoyen, Juan José, Jiménez, Miriam y Acuña, Karla. (2011). Competencias y Educación Superior. Revista Mexicana de Investigación Educativa (RMIE), 16(48), 243-266. Recuperado de: http://www.scielo.org.mx/pdf/rmie/v16n48/v16n48a11.pdf

Khun, Deanna, Amsel, Eric y O'Loughlin, Michael. (1988). The development of scientific thinking. Londres: Academic Press. 
Kress, Gunther y van Leeuwen, Theo. (1996). Reading Images: the grammar of visual design. Londres: Routledge.

Kress, Gunther, Liete-García, Regina y van Leeuwen, Theo. (2000). Semiótica discursiva. En Teun A. Van Dijk (Comp.), El discurso como estructura y proceso (pp. 373-416). Barcelona: Gedisa.

Kress, Gunther, Jewitt, Carey, Ogborn, Jon y Tsatsarelis, Charalampos. (2001). Multimodal Teaching and Learning. The Rhetorics of the Science Classroom. Advances in Applied Linguistics. Londres y Nueva York: Continuum.

Kress, Gunther. (2010). Multimodality: A social semiotic approach to contemporary communication. Londres: Routledge.

Lemke, Jay. (2008). Investigar para el futuro de la educación científica: nuevas formas de aprender, nuevas formas de vivir. Enseñanza de las Ciencias, 24(1), 5-12.

Loughran, John, Berry, Amanda y Mulhall, Pamela. (2012). Understanding and Developing Science Teachers' Pedagogical Content Knowledge. The Netherlands: Sense Publishers.

MacQueen, Kathleen, McLellan, Eleanor, Kay, Kelly y Milstein, Bobby. (1998). Codebook Development for Team-Based Qualitative Analysis. Cultural anthropology methods, 10(2), 31-36.

Manghi, Dominique. (2009). Co-utilización de recursos semióticos para la regulación del conocimiento disciplinar. Multimodalidad e Intersemiosis en el Discurso Pedagógico de Matemática en $1^{\circ}$ año de Enseñanza Media (Tesis de doctorado). Facultad de Filosofía y Educación, Pontificia Universidad Católica de Valparaíso, Chile.

Manghi, Dominique. (2013). La mediación del profesor especialista para la alfabetización semiótica en el aula de Matemática. En Estela I. Moyano (Coord.), Aprender ciencias y humanidades: una cuestión de lectura y escritura. Aportes para la construcción de un programa de inclusión social a través de la Educación Lingüística (Colección Educación, pp. 199-226). Buenos Aires, Argentina: Universidad Nacional de General Sarmiento.

Manghi, Dominique y Haas, Valentina. (2015). Uso de imágenes en clases de ciencias naturales y sociales: enseñando a través del potencial semiótico visual. Revista Enunciación, 20(2), 248-260. Recuperado de https://www.researchgate.net/publication/299443488 Uso de imagenes en clases d e ciencias naturales y sociales ensenando a traves del potencial semiotico visual

Martin, James. (2009). Boomer dreaming: the texture of re-colonisation in a lifestyle magazine. En Forey Gail y Geoff Thompson (Eds.), Text type and texture (pp. 252284). Londres: Equinox.

Martin, James y Rose, David. (2008). Working with Discourse: Meaning beyond the clase. Londres: Continuum. 
Martinec, Radan. (2004). Gestures that co- occur with speech as a systematic resource: the realization of experiencial meanings in indexes. Social Semiotics, 14(2), 193-214.

Martins, Isabel. (2006). Analisando livros didáticos na perspectiva dos Estudos do Discurso: compartilhando reflexões e sugerindo uma agenda para a pesquisa. Revista ProPosições, 17(1) (49). Recuperado de http://www.proposicoes.fe.unicamp.br/proposicoes/textos/49 dossie martinsi.pdf

Maton, Karl. (2014). Building powerful knowledge: the significance of semantic waves. En Brian Barrett, Elizabeth Rata (Eds.), Knowledge and the future of the curriculum (pp. 181-197). London: Palgrave Macmillan.

Mellado, María Elena y Chaucono, Juan Carlos. (2015). Creencias pedagógicas del profesorado de una escuela rural en el contexto mapuche. Revista Electrónica Actualidades Investigativas en Educación, 15(3). Recuperado de http://www.scielo.sa.cr/pdf/aie/v15n3/1409-4703-aie-15-03-00316.pdf

Moss, Gillian y Chamorro, Diana. (2008). La enseñanza de las ciencias sin asidero en el tiempo ni en el espacio: análisis del discurso de dos textos escolares. Revista Lenguaje, 36(1), 87-115. Recuperado de http://bibliotecadigital.univalle.edu.co/xmlui/bitstream/handle/10893/2798/Rev.\%20Leng uaje.No.36\%281\%29\%2cp.87-115\%2c2008.pdf?sequence=2

Navío, Antonio. (2006). La formación de los profesionales de la formación para el trabajo; algunos dilemas y algunas respuestas. Revista Educar, 38, 63-79. Recuperado de http://www.redalyc.org/pdf/3421/342130827004.pdf

OCDE. (2009). Revisión de Políticas Nacionales de Educación: La Educación Superior en Chile. Chile: Organización para la Cooperación y el Desarrollo Económico y el BIRD/Banco Mundial.

O'Halloran, Kay. (2007). Mathematical and Scientific Forms of Knowledge: A Systemic Functional Multimodal Grammatical Approach. En Frances Christie and Martin James (Eds.), Language, Knowledge and Pedagogy: Functional Linguistic and Sociological Perspective (pp. 205-236). Londres: Continuum.

Pozo, Juan Ignacio y Gómez, Miguel Ángel. (1998). Aprender a Enseñar Ciencia: Del conocimiento cotidiano al conocimiento científico. Madrid: Ediciones MORATA.

Rojas, María Teresa. (2014). Las creencias docentes: delimitación del concepto y propuesta para la investigación. Revista Electrónica Diálogos Educativos, 14(27), 89-112. Recuperado de: http://www.dialogoseducativos.cl/revistas/n27/rojas

Salazar, Carlos, Chiang, María Margarita y Muñoz Yohana. (2016). Competencias docentes en la educación superior: un estudio empírico en la Universidad del Bio Bío. Revista Electrónica Actualidades Investigativas en Educación, 16(1), 1-28. Recuperado de http://revistas.ucr.ac.cr/index.php/aie/article/view/22383 
Sánchez, Emilio, García, J. Ricardo, Rosales, Javier, de Sixte, Raquel y Castellano, Nadezhna. (2008). Elementos para analizar la interacción entre estudiantes y profesores: ¿Qué ocurre cuando se consideran diferentes dimensiones y diferentes unidades de análisis? Revista de Educación, (346), 105-136. Recuperado de http://www.revistaeducacion.educacion.es/re346/re346 04.pdf

Shulman, Lee. (1987). Knowledge and Teaching: Foundations of the new reform. Harvard Educational Review, 57(1), 1-23.

Shulman, Lee. (1999). Foreword. In Julie Gess-Newsome y Norman G. Lederman (Eds), Examining Pedagogical Content Knowledge: The Construct and its Implications for Science Teaching (pp. ix-ii). Dordrecht: Kluwer.

Shulman, Lee. (2004). Those Who Understand Knowledge Growth in Teaching. In The Wisdom of Practice: Essays on Teaching, Learning, and Learning to Teach (pp. 187215). San Francisco: Jossey Bass.

Stake, Robert. (2008). Qualitative case studies. En Norman K. Denzin, y Yvonna S. Lincoln (Eds.), Strategies of qualitative inquiry (pp. 119-149). Los Angeles: Sage.

Vieytes, Rut. (2004). Metodología de la Investigación en organizaciones, mercado y sociedad. Epistemología y técnicas. Buenos Aires: Editorial de las Ciencias.

Vosniadou, Stella. (1994). Capturing and modeling the process of conceptual change. Learning and Instruction, 4(1), 45-69. Recuperado de http://citeseerx.ist.psu.edu/viewdoc/download?doi=10.1.1.541.5078\&rep=rep1\&type=pd $\underline{f}$

Vygotsky, Lev. (1979). El desarrollo de los procesos psicológicos superiores. Barcelona: Grijalbo.

Vygotsky, Lev. (1987). Thinking and speech. En Robert W. Rieber y Aaron S. Carton (Eds.), The collected works of Lev Vygotsky (Trad.por N. Minick; pp. 41-284). Nueva York, Plenum Press. 